Article

\title{
An Investigation of Friction Coefficient on Microstructure and Texture Evolution of Interstitial-Free Steel during Warm Rolling and Subsequent Annealing
}

\author{
Hongbo Pan ${ }^{1,2, *}$, Yong Wan ${ }^{3}$, Huiting Wang ${ }^{3}$, Xiaohui Shen ${ }^{3}$, Bin Fu ${ }^{4, *}$, D. Y. $\mathrm{Li}^{2}$, \\ Yongjuan Dai ${ }^{5}$ and Jun Yan ${ }^{1,2}$ \\ 1 Key Laboratory of Metallurgical Emission Reduction \& Resources Recycling of Ministry of Education, \\ Anhui University of Technology, Ma'anshan 243002, China; yanjun@ahut.edu.cn \\ 2 The Department of Chemical and Materials Engineering, University of Alberta, Edmonton, AB T6G2H5, \\ Canada; dongyang.li@ualberta.ca \\ 3 School of Metallurgy Engineering, Anhui University of Technology, Ma'anshan 243000, China; \\ wanyong0729@163.com (Y.W.); wgwht@nuaa.edu.cn (H.W.); sxh@ahut.edu.cn (X.S.) \\ 4 School of Materials Science and Engineering, Shanghai Institute of Technology, Shanghai 201418, China \\ 5 School of Materials Science and Engineering, Hebei University of Science and Technology, \\ Shijiazhuang 050018, China \\ * Correspondence: 20130007@ahut.edu.cn (H.P); fubin@sit.edu.cn (B.F.)
}

Received: 2 October 2019; Accepted: 25 October 2019; Published: 27 October 2019

\begin{abstract}
A Ti bearing interstitial-free steel was finishing rolled in the ferrite region with and without lubrication and microstructures, mechanical properties and textures evolution during warm rolling and subsequent annealing were investigated by OM, SEM, tensile test and ODF. The results show that the surface microstructure of the as-rolled specimen without lubrication is composed of dense shear bands, while the microstructures of the central layer of the as-rolled specimen without lubrication and the whole cross section of the as-rolled specimen with lubrication are elongated ferrite. Short-time annealing can make the non-lubricated rolling sample recrystallize, but the lubricated rolling sample cannot. After complete recrystallization, the microstructure of the surface layer of the as-annealed specimen without lubrication is finer than that of the center layer of the as-annealed specimen without lubrication and the whole section of the as-annealed specimen with lubrication. The mechanical properties of as-annealed sample without lubrication change significantly in the initial annealing stage, while that of as-annealed sample with lubrication remain unchanged until the end stage of annealing. The surface layers of the as-rolled samples have strong Goss component and weak $\gamma$ fibre components, while the central layers have strong $\gamma$ fibre components and moderate rotated cubic components. As annealing proceeds, the Goss components of the surface layer decrease and the $\gamma$ fibre components increase. The rotated cubic components in the central layer are gradually transformed into $\gamma$ texture.
\end{abstract}

Keywords: warm rolling; lubrication; microstructure evolution; texture; shear bands

\section{Introduction}

Interstitial-free (IF) steel is the third generation of deep-drawing steels used by the Automobile and Home Appliances industry after Al-killed steel. It exhibits excellent deep drawability with high plastic strain ratio, high elongation (El), high harden index, and low yield ratio [1]. Traditionally, Ultra-Low Carbon (ULC) and IF steel are hot rolled in the austenite region, and hot rolled products are further cold rolled to produce the desired shape and properties. This is usually followed by an annealing process, in which texture and properties are controlled. Ultra-low carbon steel and IF steel as-rolled products 
produced by traditional hot rolling have random orientations and poor deep-drawing properties. However, as a new process with both advantages of hot rolling and cold rolling, warm rolling has attracted the interests of researchers. As a potential process to obtain advantageous microstructure such as ultrafine structure, to offer an excellent comprehensive mechanical property, warm rolling of magnesium alloy, shape memory alloy and tool and die steel has been actively studied [2-5]. Recently, attention has also been directed toward the warm rolling process of medium $\mathrm{Mn}$ steel in an attempt to further improve its mechanical properties and/or to reduce the traditional procedure including hot rolling, cold rolling and intercritical-annealing [6-10]. As early as more than 10 years ago, warm rolling technology also attracted the attention of researchers in IF steel. At that time, the main problem was how to control the chemical composition and rolling process to enhance the ND//rolling texture components and improve the deep-drawing property of the final product [11-17]. However, the traditional hot rolling process has some shortcomings, such as the production of thin-gauge products and the long residence time for temperature during ferrite rolling, which has meant that the technology has not been further explored and popularized in IF steel.

In the past decade, with the development of metallurgical technology (especially clean steel metallurgical technology) and the requirement of energy saving and consumption reduction, the steel industry has gradually developed to a short process, which has resulted in the emergence of thin slab continuous casting and rolling technologies such as Inline Strip Production (ISP) and Endless Strip Production (ESP) [18]. Compared with the traditional hot-rolled slab process, ESP technology has the advantages of short process, less investment, low energy consumption, less emissions, uniform microstructure and properties of through steel sheet, and stable production of $0.8 \mathrm{~mm}$ thickness products [19]. Based on these advantages, ESP technology has been developed rapidly in Europe and China in recent years [20]. Ferrite region rolling with ESP can reduce induction heating and residence time between rough rolling and finishing rolling, further save energy consumption and increase productivity, and has the appearance and mechanical properties comparable to cold rolling products. Therefore, this technology is a promising alternative for cold rolling in thin-gauge deep-drawing steel sheet.

However, researchers have found that the friction between roll and steel sheet during warm rolling will produce shear deformation on the surface of steel sheet and form a strong shear texture component, which is unfavorable to deep-drawing performance [21,22]. Therefore, lubrication is essential to reduce friction in rolling process to improve $\gamma$ fibre components. Although some researchers have explored lubrication rolling technology in ferrite region in the past, the research work mainly focuses on the qualitative relationship between friction and shear texture strength and plastic strain ratio [21,23-27]. The uniformity of microstructure and texture and its evolution mechanism during rolling and subsequent annealing under lubrication conditions have not been systematically studied. The aim of the study is to gain further insight into the effect of the lubricated rolling on microstructure and texture uniformity and evolution law and mechanism during subsequent annealing.

\section{Experimental Procedure}

The chemical composition of the experimental steel is listed in Table 1. The interstitial-free steel was received from a commercial steel company in the form of offcuts from the continuous casting billet. These steels were forged down to blocks $35 \mathrm{~mm}$ thick, $100 \mathrm{~mm}$ in width and $100 \mathrm{~mm}$ in length. The samples were reheated for $30 \mathrm{~min}$ at $1100{ }^{\circ} \mathrm{C}$. The first stage deformation was applied with a $45 \%$ reduction to simulate the rough rolling at $1000{ }^{\circ} \mathrm{C}$, which included three passes. The samples were then rolled into final $4.0 \mathrm{~mm}$ thickness hot band was followed by holding at $600{ }^{\circ} \mathrm{C}$ for $2 \mathrm{~h}$ and furnace-cooled to simulate coiling in all cases, with only the lubrication conditions being varied. Finishing rolling temperature was $700{ }^{\circ} \mathrm{C}$ and finishing rolling passes were 4 passes. The rolling pressures during finishing were recorded. The lubrication conditions were varied by using or not using Quaker lubricant oil. In order to investigate microstructure and texture development in the initial stages of recrystallization and in the fully recrystallization, strips were also annealed at $820^{\circ} \mathrm{C}$ for $7 \mathrm{~min}$ and $50 \mathrm{~min}$ in a box furnace respectively. 
Table 1. Chemical composition of the tested steel ( $w \mathrm{t} \%)$.

\begin{tabular}{cccccccc}
\hline $\mathbf{C}$ & $\mathbf{S i}$ & $\mathbf{M n}$ & $\mathbf{P}$ & $\mathbf{S}$ & $\mathbf{T i}$ & $\mathbf{N}$ & Als \\
\hline 0.0023 & 0.02 & 0.12 & 0.007 & 0.005 & 0.057 & 0.0026 & 0.022 \\
\hline
\end{tabular}

Surfaces of as-rolled samples were observed by scanning electron microscope, and microstructures of as-rolled and as-annealed specimens were observed by ZEISS AX10 optical microscopy and scanning electron microscope (Zeiss, Wangen, Germany). The SEM study was conducted using a LEO-1450 microscope (Zeiss, Cambridge, UK). Samples for observing microstructure were sectioned perpendicular to the transverse direction and electropolished in $10 \%$ perchloric acid, they were then etched in $3 \%$ nital for $10 \mathrm{~min}$. In order to clarify more clearly the effect of lubrication conditions on the microstructure evolution, microstructures were observed along the thickness of the as-rolled and as-annealed samples, and then combined with CoreDraw software to obtain the metallographic microstructures of the whole thickness direction. The standard mechanical properties were determined using ASTM A370-2017 standard specimens having a gauge length of $50 \mathrm{~mm}$ on an MTS universal tensile test machine with $2 \mathrm{~mm} / \mathrm{min}$ loading rate (MTS, Cary, North Carolina, CO, US).

For texture measurement, surface and mid-thickness as-rolled and as-annealed specimens with and without lubricant were prepared by machining, paper grinding, and electropolishing. Three incomplete pole figures $(\{110\},\{200\}$ and $\{112\})$ were measured using the reflection technique on an automatic Siemens D5000 texture goniometer. The orientation distribution functions (ODF's) were then evaluated using the Bunge series expansion method [28]. Finally, The experimental textures were illustrated in the form of a $\varphi_{2}=45^{\circ} \mathrm{ODF}$ section as shown in Figure 1.

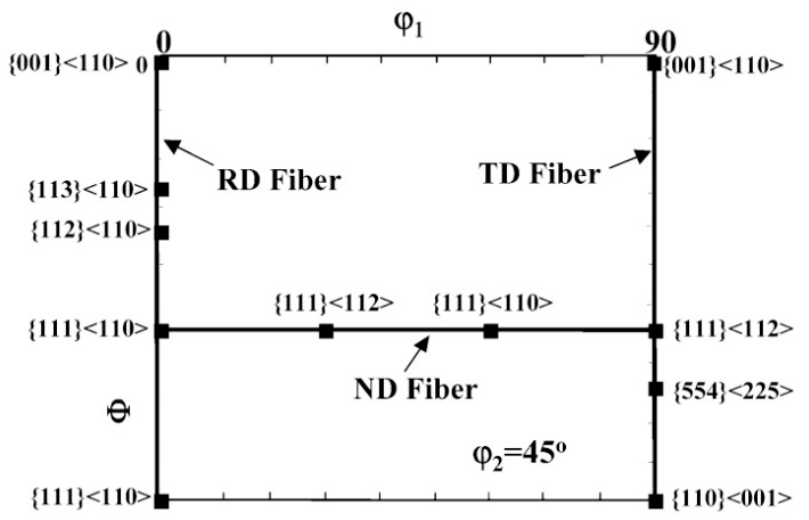

Figure 1. $\varphi_{2}=45^{\circ} \mathrm{ODF}$ sections showing some important orientations relevant for b.c.c (Body Center Cubic). crystals.

\section{Results}

\subsection{Surface Appearance}

The surface appearances of the specimens with or without lubrication are shown in Figure 2. The surface appearance of the sample without lubrication is rough and uneven, and has many cracks, as shown in Figure 2a. However, the surface appearance of the specimen with lubrication is generally flat, and there are some fine oxides and cracks locally, as shown in Figure $2 \mathrm{~b}$. As can be seen from the local enlarged photograph at location A in the figure, the surface of the specimen without lubrication is composed of many pits and bulges with different sizes, as shown in Figure 2c. The local magnified appearance of oxide on the specimen with lubrication is consistent with that of the specimen without lubrication. However, the pits and bulges on the surface without oxidized particles are smaller and shallower, as shown in Figure 2d. The main reason for this phenomenon is that the surface of the roll is actually uneven due to wear and tear [29]. During the rolling process, the surface of the roll will be 
replicated to the sample, which makes the surface of the sample uneven. On the contrary, under the condition of oil-water mixed lubrication, the hot rolling lubricant will form a discontinuous directional adsorption film between the surface of the roll and the sample, which effectively fills the pits of the roll and reduces the surface rough appearance of the sample $[30,31]$.
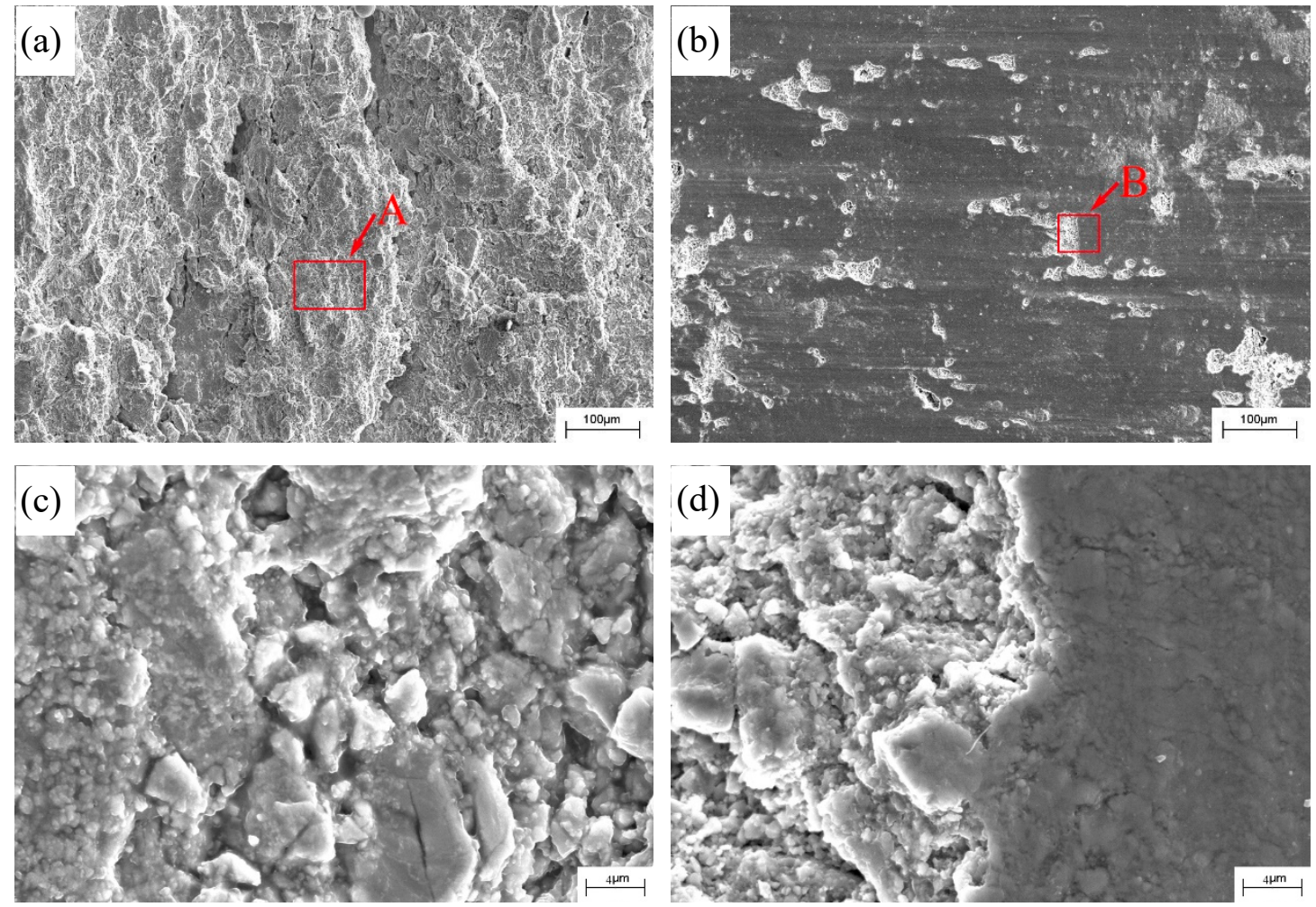

Figure 2. Surface appearances of specimens without lubrication (a) and with lubrication (b) respectively; $(\mathbf{c}, \mathbf{d})$ are locally enlarged morphologies of A and B respectively.

\subsection{Microstructure}

The optical microstructures from the surface to the center of the as-rolled and different time annealed specimens are shown in Figures 3 and 4, respectively. In all the specimens, the ferrite grains were elongated along the rolling direction, and S-shaped curved grains were present, as shown in Figure 3. However, the lubricated rolled sample contained the smallest number of such grains; conversely the non-lubricated rolled sample had the highest fraction of such curved grains. The ferrite grain thickness in the whole cross section of lubricated rolled specimens is uniform and fine. Whereas the ferrite grain thickness in the whole cross section of the non-lubricated rolling sample is not uniform, the ferrite grain thickness in the center is larger and the surface is very thin, which presents gradient relationship. Shear bands were observed on the surface of non-lubricated rolled specimens and were dense, while no obvious shear bands were observed on the surface of lubricated rolled specimens.

The specimen without lubrication that was annealed for $7 \mathrm{~min}$ shows a non-uniform microstructure throughout the thickness, and fine recrystallized grains can be seen in the near-surface severely sheared region, no recrystallization was occurred in the center. As shown in Figure 4a. However, the specimen with lubrication that was annealed for 7 min shows the same morphology as hot-rolled specimens, no recrystallized microstructure was found in the whole cross section of the specimen. As shown in Figure $4 \mathrm{~b}$. After annealing at $820^{\circ} \mathrm{C}$ for $50 \mathrm{~min}$, recrystallization was completed throughout thickness of the specimens with or without lubrication. For non-lubricated rolled specimen, the grain size of the near-surface layer is smaller than that of the center, which shows that the inhomogeneous deformation affects the size of recrystallized grains. As shown in Figure 4c. Conversely, uniform grain size is 
obtained in the surface layer and the center of the specimen with lubrication, and it is larger than that of non-lubricated specimens. As shown in Figure $4 \mathrm{~d}$.

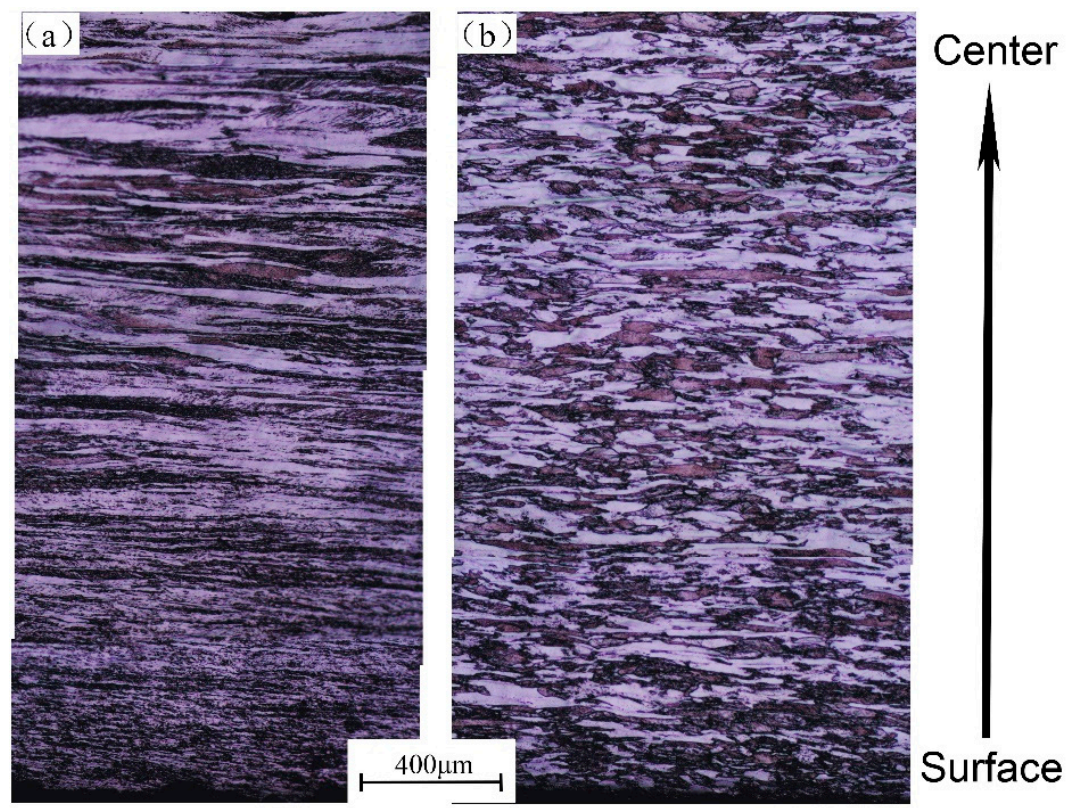

Figure 3. Optical microstructures of as-rolled specimens without lubrication (a) and with lubrication (b) respectively.
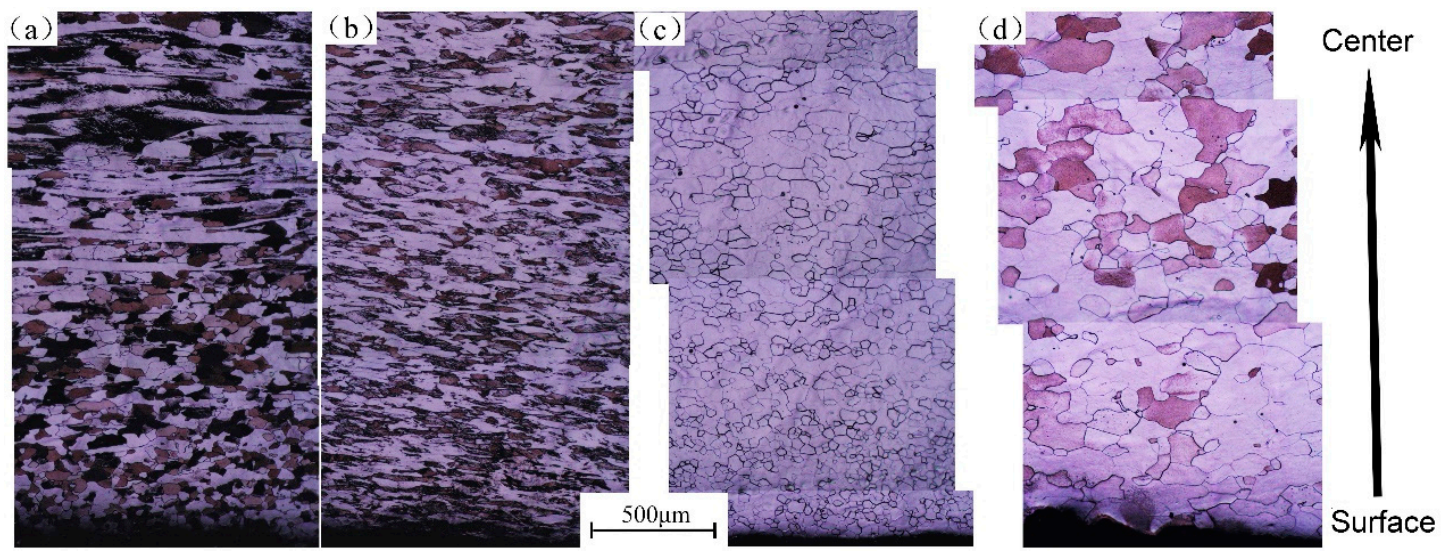

Figure 4. Optical microstructures of specimens with and without lubrication annealed at $820^{\circ} \mathrm{C}$ for different time. Non-lubricated specimens annealed for $7 \mathrm{~min}$ (a) and $50 \mathrm{~min}$ (c) respectively; Lubricated specimens annealed for $7 \mathrm{~min}(\mathbf{b})$ and $50 \mathrm{~min}(\mathbf{d})$ respectively.

SEM images near the surface of as-rolled specimens without and with lubrication are shown in Figure 5. The ferrite grains of the sample without lubrication are obviously elongated and refined, the thickness of ferrite grain is about $2 \mathrm{um}$. Two different types of ferrite grains were found in the microstructure, one is the absence of shear bands in grains, the other is the presence of dense short shear bands in grains. As shown in Figure 5a. However, The ferrite grains of the sample with lubrication are relatively coarse, and the ferrite grain thickness ranges from 10 to $20 \mathrm{um}$. No shear band and three different shear bands were found in ferrite grains. The first morphological type consists of continuous parallel lines; and they traverse entire grains and are inclined at $15-40^{\circ}$ to the rolling direction. This type of shear band is referred to here as a "long shear bands". The second type appears in the form of discontinuous lines, they were restricted to the interior of the grains but their macroscopic orientations were similar to those of the "long shear bands", they are identified as a "short shear bands". The third 
type are inclined at $15-40^{\circ}$ to the rolling direction in the form of continuous wavy line and is classified as "intense long shear bands" [11]. As shown in Figure 5b.
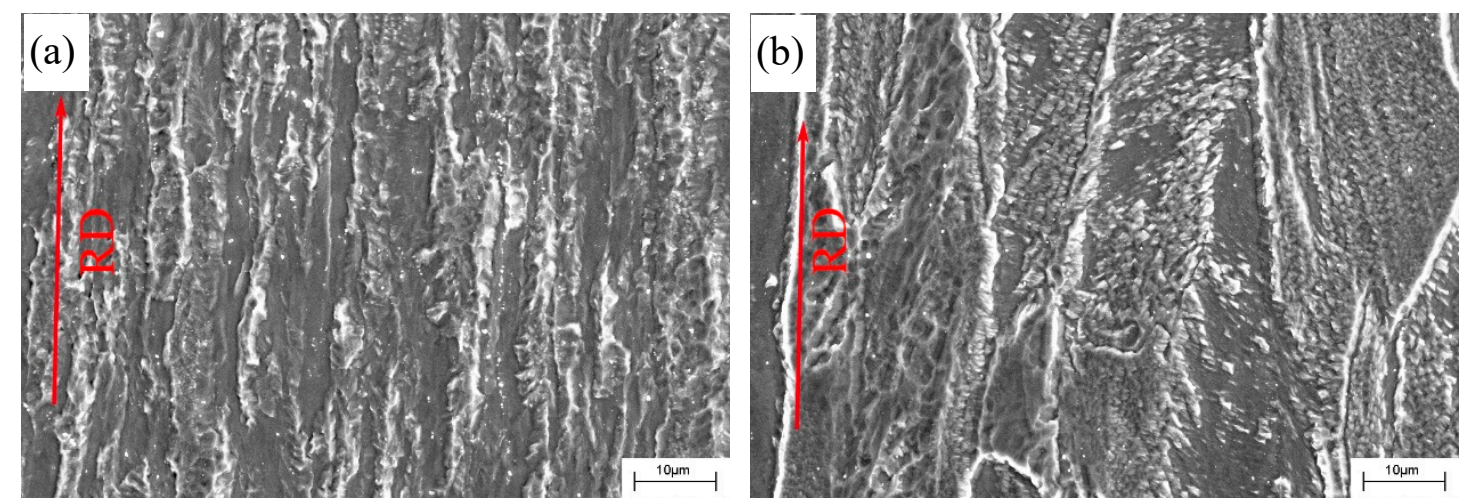

Figure 5. SEM images near the surface of as-rolled specimens without lubrication (a) and with lubrication (b) respectively.

SEM images of specimens with and without lubrication annealed at $820^{\circ} \mathrm{C}$ for $7 \mathrm{~min}$ are shown in Figure 6. As can be seen from Figure 6, except that the microstructure of the surface of specimen without lubrication is composed of equiaxed recrystallized grains, the other microstructures of specimens are composed of elongated pancake-shaped grains along the rolling direction. Microstructures of the surface and the center of the specimen with lubrication are uniform, and the ferrite grain thickness is smaller than that of the center of specimen without lubrication. This indicates that recrystallization occurs only on the surface of sample without lubrication at $820^{\circ} \mathrm{C}$ annealed for $7 \mathrm{~min}$.
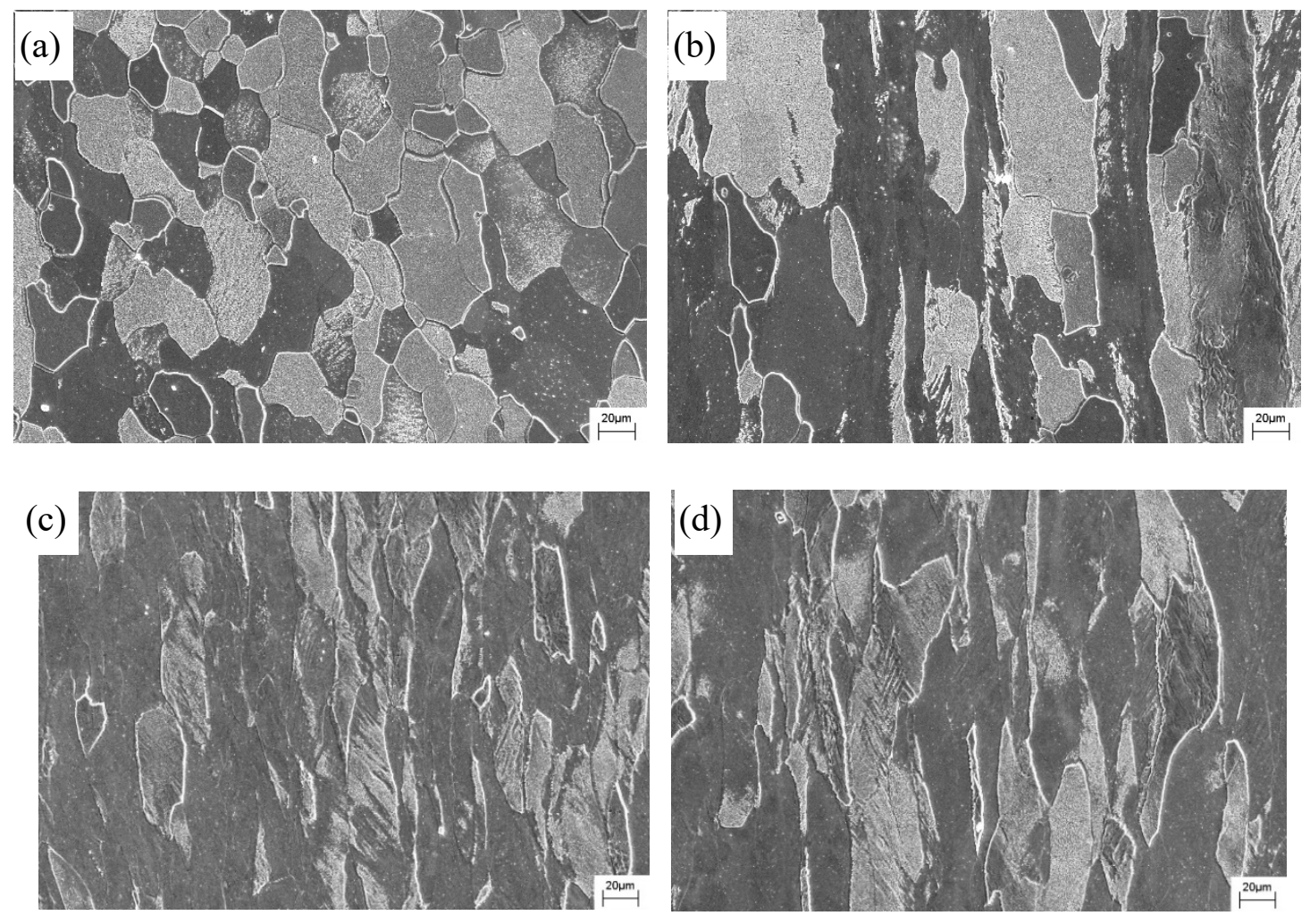

Figure 6. SEM images of specimens with and without lubrication annealed at $820{ }^{\circ} \mathrm{C}$ for $7 \mathrm{~min}$. the surface (a) and the center (b) of specimen without lubrication respectively; the surface (c) and the center (d) of specimen with lubrication respectively. 


\subsection{Mechanical Properties}

The stress-strain curves of the as-rolled and different time annealed samples with and without lubrication are presented in Figure 7. This figure shows the effect of lubrication and annealed time on the tensile strength and elongation of the tested steel sheets. The tensile results presented in Figure $7 \mathrm{a}$ show that the tensile strength decreased slightly and elongation increased slight under lubrication condition. The main reason for this phenomenon is that the surface shear deformation is more serious in as-rolled sample without lubrication. As can been found in Figure 3. When annealed for $7 \mathrm{~min}$, the tensile strength and elongation of the sample with lubrication are the same as that of as-rolled one; however, the tensile strength is obviously decreased and the elongation is obviously increased to the sample without lubrication. As shown in Figure $7 \mathrm{~b}$. In the case of short-time annealing, the recrystallization process has begun in the non-lubricated rolling samples with severe shear deformation, but not in the lubricated rolling samples. As illustrated in Figure 4a,b. Figure 7c shows the same mechanical properties of the specimens with or without lubrication, both of them have been fully recrystallized in the case of long-time annealing, as presented in Figure 4c,d.
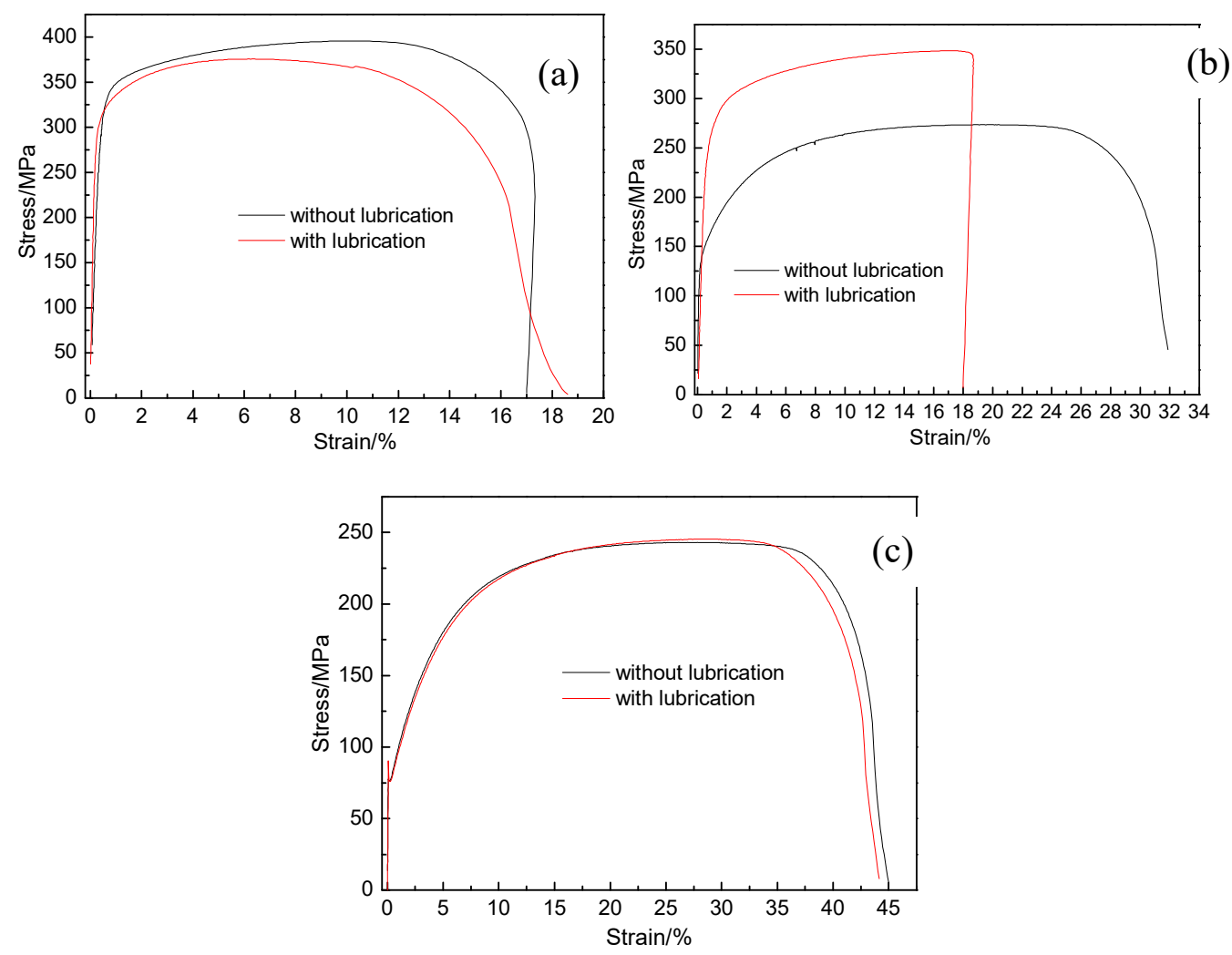

Figure 7. Stress-strain curves of as-rolled and different time annealed specimens with and without lubrication. As-rolled (a), annealed for $7 \mathrm{~min}(\mathbf{b})$ and $50 \mathrm{~min}(\mathbf{c})$ respectively.

\subsection{Texture}

The corresponding texture results of as-rolled specimens with and without lubrication, in the form of $\varphi_{2}=45^{\circ}$ ODF sections, are illustrated in Figure 8. Because the rolling temperature is in the ferrite region, the texture type is similar to that of cold rolling. The central textures of the specimens all contained the two principal rolling components: the $\alpha$-fibre with $<110>$ parallel to the rolling direction and the $\gamma$-fibre with $<111>$ parallel to the normal direction. This result is independent of the lubrication conditions, a characteristic feature of these results is that the ND fibres have the strong texture intensity and the RD fibres have moderate intensity of the rotated cube component, as shown in Figure $8 b$,d. However, the orientation of the surface is completely different from that of the center. 
The strong Goss $\{110\}<001>$ texture and weak $\gamma$-fibre were developed in the surface region when lubricant was not used, as shown in Figure 8a. However, the strong Goss texture and moderate $\gamma$-fibre were developed in the surface for lubricated rolling, as shown in Figure 8c.
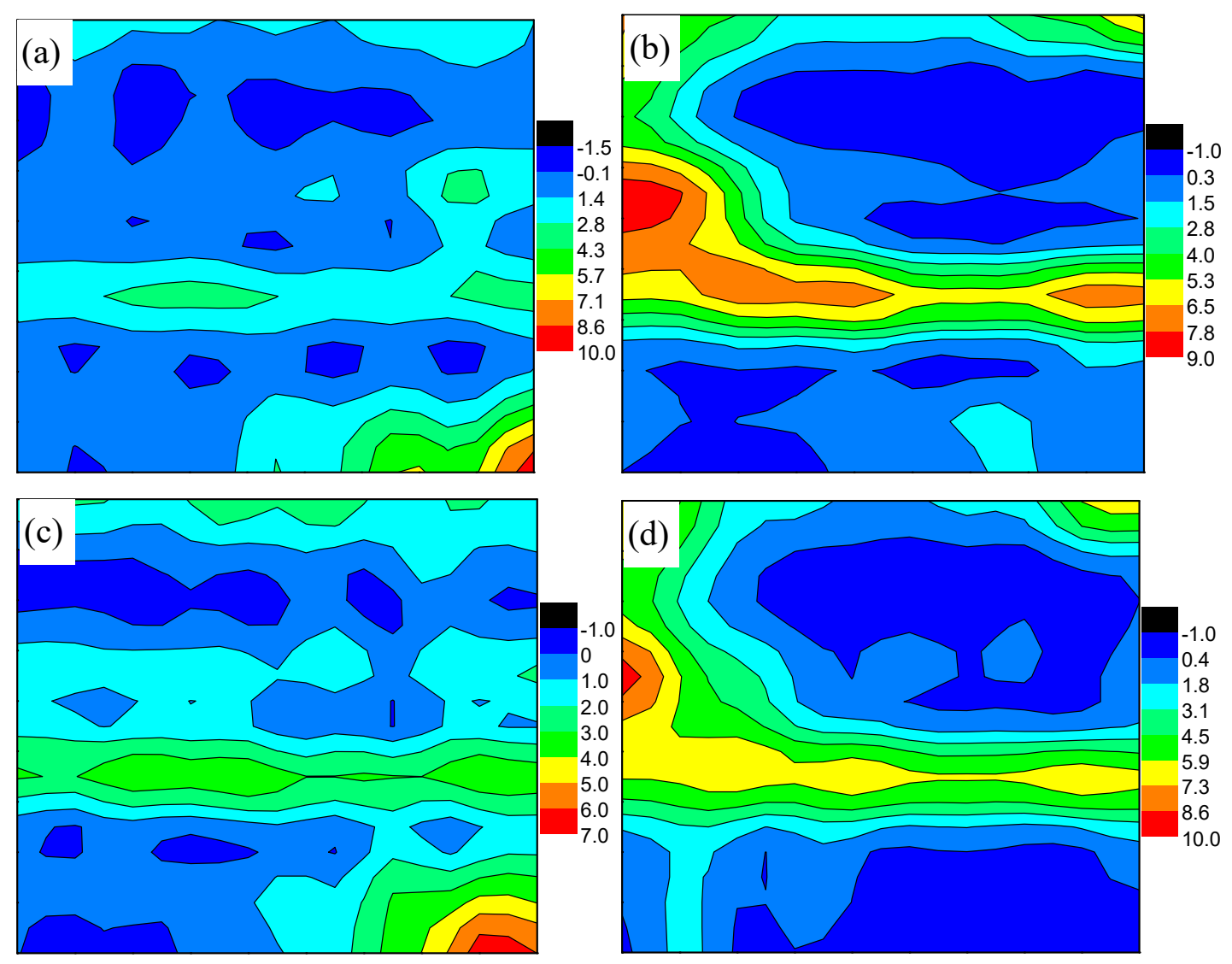

Figure 8. $\varphi_{2}=45^{\circ}$ sections of the ODFs for the as-rolled samples. the surface (a) and the center (b) of the sample without lubrication; the surface (c) and the center (d) of the sample with lubrication.

Typical ODFs of the as-annealed specimens with and without lubrication at $820^{\circ} \mathrm{C}$ annealed for $7 \mathrm{~min}$ are given in Figure 9. It can readily be observed from Figures 8 and 9 that the same texture components having similar intensities are present for the center of the as-rolled and as-annealed specimens. There are, however, some variations in the texture components and the intensities for the surface of as-rolled and as-annealed specimens. Compared with as-rolled specimens, the intensities of Goss texture decrease and that of $\gamma$-fibre texture increase. Moreover, the Goss texture is disappeared and a moderate intensity of the rotated cube component is appeared in the surface with lubrication after $820^{\circ} \mathrm{C}$ annealed for $7 \mathrm{~min}$. 

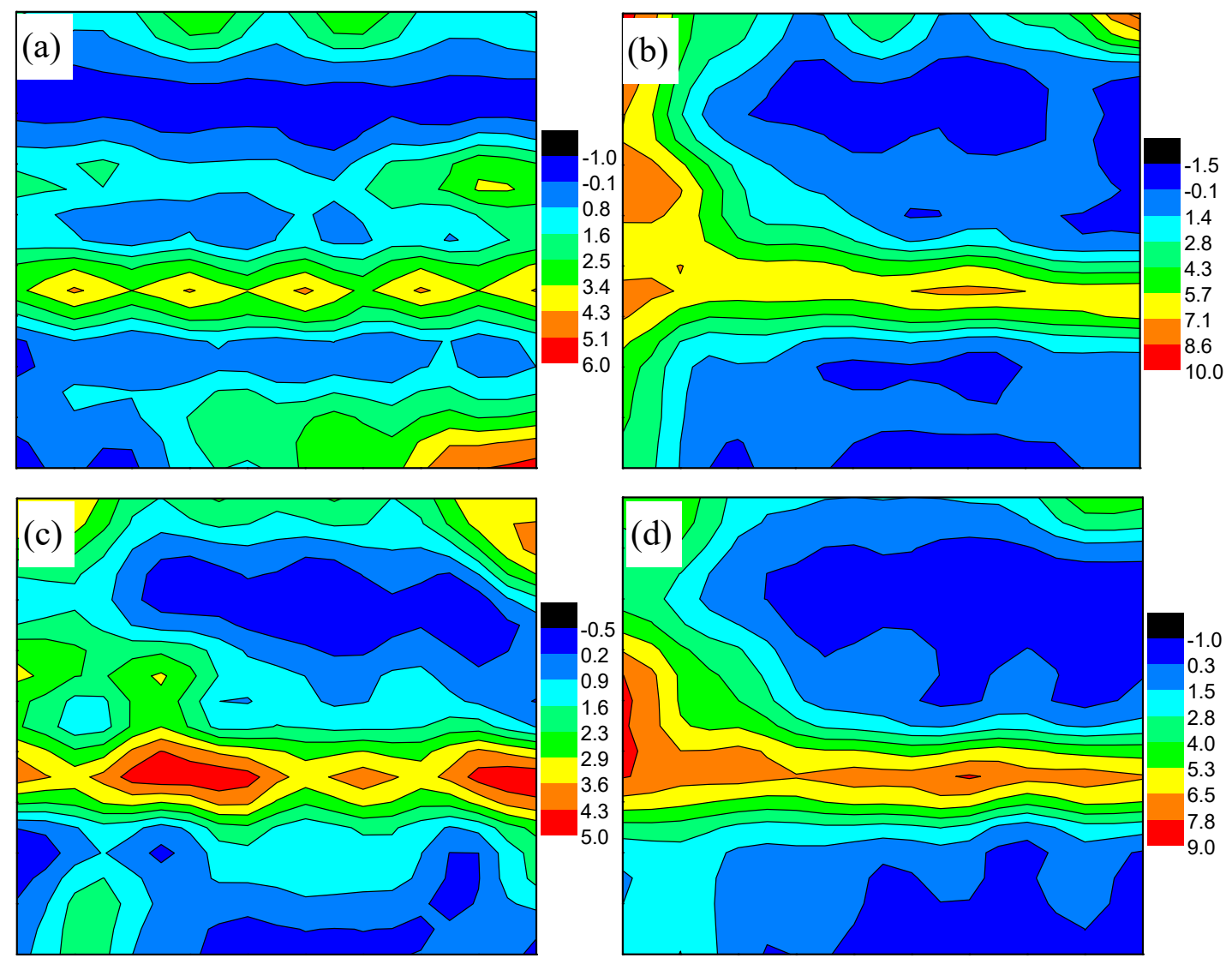

Figure 9. $\varphi_{2}=45^{\circ}$ sections of the ODF's for the as-annealed samples at $820^{\circ} \mathrm{C}$ for $7 \mathrm{~min}$. the surface (a) and the center (b) of the sample without lubrication; the surface (c) and the center (d) of the sample with lubrication.

After $820^{\circ} \mathrm{C}$ annealed for $50 \mathrm{~min}$, the recrystallized textures of specimens with and without lubrication, in the form of $\varphi_{2}=45^{\circ}$ ODF sections, are illustrated in Figure 10. Compared with the results mentioned above, the intensities of the $\gamma$ fibres texture components increase sharply while the intensities of the rotated cubic orientation components decrease dramatically in the center of the samples with and without lubrication. However, in addition to the previous orientation, some other orientations have also appeared in the surface of the samples.


Figure 10. Cont. 


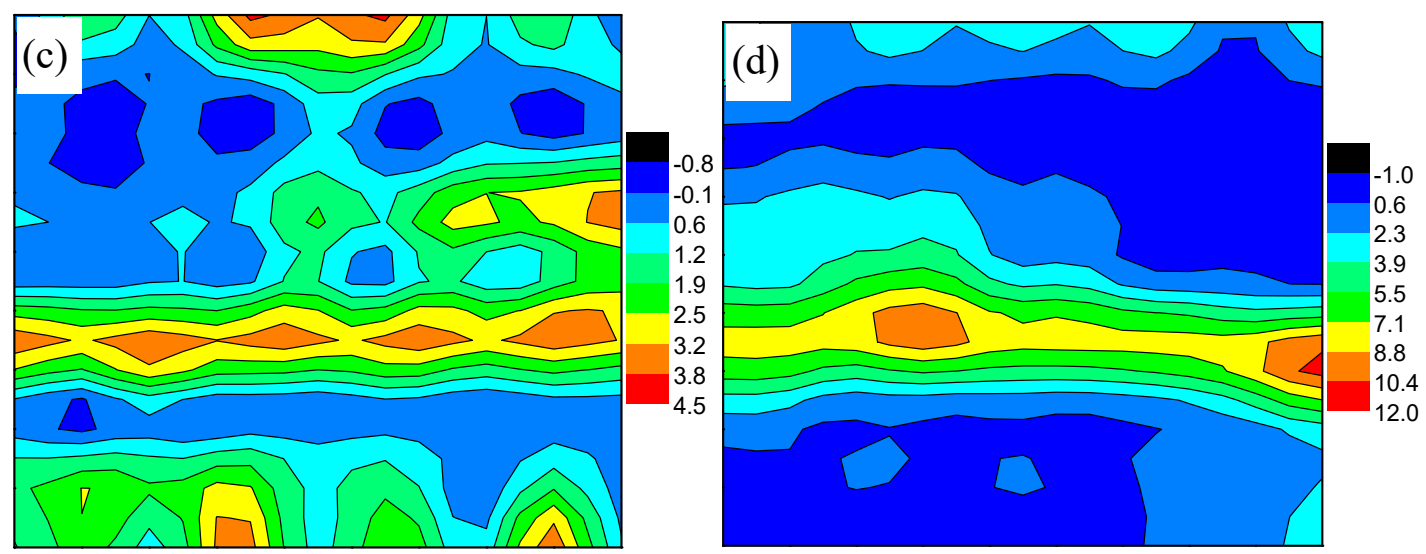

Figure 10. $\varphi_{2}=45^{\circ}$ sections of the ODFs for the as-annealed samples at $820^{\circ} \mathrm{C}$ for $50 \mathrm{~min}$. the surface (a) and the center (b) of the sample without lubrication; the surface (c) and the center (d) of the sample with lubrication.

In order to study the effect of lubrication conditions on the orientation of components during subsequent annealing in more detail, area fraction of different orientations components in the as-annealed specimens at $820^{\circ} \mathrm{C}$ for different times are shown in Figure 11. This figure indicates the importance of the lubrication, since the highest content of the $\gamma$ fibres components and the lowest content of the Goss orientation components are obtained when the lubrication is conducted during warm rolling. Increasing recrystallization further increases area fraction of the $\gamma$ fibres components. The effect of the recrystallization, however, is minimal if no lubrication is used in warm rolling. The $\gamma$ fibre components and rotated cubic components are main orientations in the center of specimen without lubrication and whole section of specimen with lubrication when the specimens are annealed at $820^{\circ} \mathrm{C}$ for $7 \mathrm{~min}$, whereas the surface of specimen without lubrication has a relatively high fraction of Goss orientation component. The rotated cubic orientation components decrease gradually and are replaced by the $\gamma$ fibre components when the recrystallization process is completed gradually.
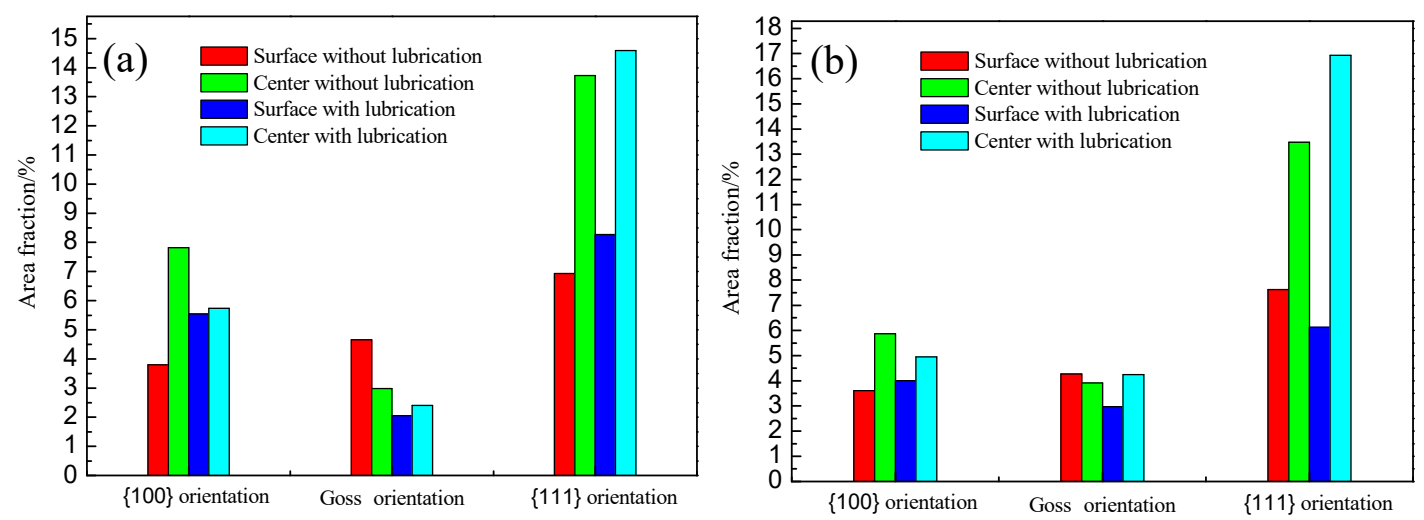

Figure 11. Area fraction of different orientations components annealed at $820^{\circ} \mathrm{C}$ for $7 \mathrm{~min}(\mathbf{a})$ and $50 \mathrm{~min}(\mathbf{b})$.

\section{Discussion}

The inhomogeneities of microstructure and texture are the microcosmic reflection of stress and strain. In order to better understand the causes of these phenomena, the rolling pressures during finishing rolling were measured. The finishing rolling pressures with or without lubrication are given in Figure 12. It can be easily seen that under all the same other conditions, the rolling pressure can be greatly reduced by using lubrication rolling. The increased rolling pressure is mainly subject to friction between the roll and the workpiece. Therefore, the specimen surface will undergo intense shear deformation during non-lubricated rolling, which corresponds to the microstructure of Figure 3 a. 


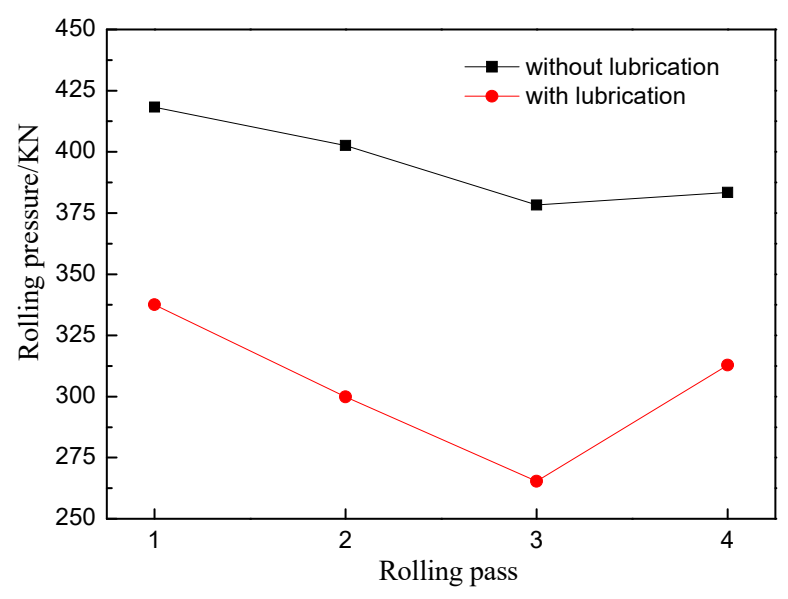

Figure 12. Rolling pressure in finishing rolling process.

Additional shear strain is proportional to friction force between rolls and materials reported by Matsuoka [24]. The additional shear strain plays an important role in the uniformity of metal flow and the formation of shear bands during the deformation [32], which further affects the development of microstructure and texture. The relationships between the morphologies of the shear bands and the characteristics of the rolling fibres have been studied by Timokhina [11]. The long, short and intense long shear bands are linked to the presence of a well-developed $\gamma$-fibre. An increase in the proportion of these shear bands can cause the relative scarcity of both the short shear bands. In addition, it decreases the severity of the shear bands, which is beneficial as heavy ingrain shear band is detrimental to formation of the desirable $\{111\}$ texture component during subsequent process.

Generally, slip takes place on $\{110\},\{112\}$ and $\{123\}$ crystal planes for ferrite structure, but $\{110\}$ and $\{112\}$ planes are mainly slip planes [33]. Both $\{110\}$ and $\{112\}$ slip planes have the same rotation axis $<110>$. During deformation, the crystalline orientation aggregates in the vicinity of $\{001\}<110>$ and then spreads to $\{112\}<110>$ and $\{111\}<110>$ along the $\alpha$ fibres [34]. The grain orientation aggregation near $\{111\}<112>$ lags behind the $\alpha$ fibres. However, the shear strain mainly concentrates on the surface of the steel sheet during non-lubricated rolling, which hinders the convergence of grain orientation in the $\alpha$ fibres and the $\gamma$ fibres components. At this time, the normal crystallographic slip is strongly inhibited, and the shear bands develop with a non-crystallographic geometry, which forms strong Goss orientation components $[35,36]$. Consequently, the surface layer of as-rolled specimens without lubrication has the strong $\{110\}<001>$ texture components and weak $\gamma$-fibre and rotated cubic texture components, while the surface layer of as-rolled specimens with lubrication has the moderated $\{110\}$ $<001>$ texture components and weak $\gamma$-fibre and rotated cube texture components. Instead, the center layers of as-rolled specimens with and without lubrication have the strong $\gamma$-fibre texture components and moderated rotated cubic texture components, as shown in Figure 8.

When recrystallization proceeds, the Goss orientation recrystallized grains preferentially appear in the shear bands and form strong Goss orientation components through sub-grain nucleation and growth. Cubic orientation recrystallized grains also nucleate in the shear band, but the nucleation density is lower than that of Goss oriented grains. The center of the steel sheet is immune to shear stress. The recrystallized grains of the orientation $\{111\}<112>$ are preferred to nucleation and growth in the orientation $\{112\}<110>$ and $\{111\}<110>$ deformed grains. that is to say, the recrystallized grains of $\gamma$ fibres components consume $\alpha$ fibres and other random orientation grains during nucleation and growth [37]. In the process of recrystallization grain growth, the Goss and $\{111\}<112>$ components are mutual competing orientation components [38]. In the early stage of recrystallization, the high storage energy of shear band is beneficial to the formation of Goss orientation recrystallized grains [39]. However, after recrystallization, the storage energy of shear band decreases, the storage energy difference in different deformed grains decreases, and the growth rate of Goss orientation grains slows 
down. In addition, most of the recrystallized grains with Goss orientation distribute continuously, and have a large number of small-angle grain boundaries. The grain boundaries migrate slowly and the grains are not easy to grow [38]. On the contrary, the ND orientations $\{111\}<112>$ and $\{111\}<110>$ recrystallized grains distribute uniformly, and the grain boundary migration is fast. They consume the surrounding grains and grow up. Therefore, as annealing proceeds, the Goss texture component of the surface layer decreases gradually, and the $\gamma$ fibre component of the surface layer increases. While the rotated cubic components of the center layer gradually transform to the $\gamma$ fibre components, which further strengthens the $\gamma$ fibre texture of the center layer. Finally, there are moderate $\gamma$ fibre components and weak Goss texture component in the surface, and stronger $\gamma$ fibre components in the center, as shown in Figures 9 and 10.

\section{Conclusions}

The effect of lubrication condition on microstructural characteristics and texture evolution of interstitial-free steel during warm rolling and subsequent annealing were studied. The conclusions obtained are as follows.

(1) The rolling pressures in lubricated rolling are obviously less than that in non-lubricated rolling. The surface appearance of the sample without lubrication is rough and uneven, and has many cracks. However, the surface appearance of the specimen with lubrication is generally flat, and some fine oxides and microcracks scattered on the surface locally.

(2) The tensile strength of as-rolled sample without lubrication is slightly higher than that of as-rolled sample with lubrication, while the elongation is slightly lower. In the early stage of annealing, the mechanical properties of as-annealed sample with lubrication are the same as that of as-rolled sample, while the tensile strength is obviously decreased and elongation is obviously increased for as-annealed sample without lubrication. At the later stage of annealing, the mechanical properties of as-annealed samples with or without lubrication are the same, the strength is significantly decreased and the elongation is significantly increased.

(3) The microstructure of the surface layer of the as-rolled sample without lubrication is obviously different from that of the central layer. The microstructure of the surface layer is mainly composed of fine and dense shear bands with thin ferrite thickness, while that of the central layer is composed of elongated ferrite grains with thick ferrite thickness. The microstructures of the as-rolled sample with lubrication are uniform and consist of elongated ferrite with thick ferrite thickness.

(4) After annealing at $820^{\circ} \mathrm{C}$ for $7 \mathrm{~min}$, recrystallization has occurred in the surface layer of the specimen without lubrication, and the microstructure is equiaxed ferrite. No recrystallization has occurred in the central layer of the specimen without lubrication and the specimen with lubrication. When annealed at $820^{\circ} \mathrm{C}$ for $50 \mathrm{~min}$, recrystallization occurs in all specimens, and the microstructures are equiaxed ferrite. However, the microstructures of the specimen with lubrication are uniform. Conversely, the microstructure of the surface layer of the sample without lubrication is finer and that of the central layer is larger.

(5) The surface layers of the as-rolled specimens are mainly composed of strong Goss component and weak $\gamma$ fibre components. The surface layer of the as-rolled specimen without lubrication has stronger Goss component than the specimen with lubrication. The central layers of the as-rolled samples are composed of strong $\gamma$ fibres and moderate rotated cubic components. With the annealing process, the Goss component in the surface layer decreases gradually and the $\gamma$ fibre components increase gradually. The rotated cubic components in the center layer gradually transform into $\gamma$ fibre components; the $\{111\} /\{100\}$ of the sample with lubrication is larger than that of the sample without lubrication.

Author Contributions: References, X.S. and D.Y.L.; methodology, B.F. and Y.D.; software, X.S.; validation, H.P., J.Y. and X.S.; formal analysis, H.P. and Y.W.; investigation, B.F. and H.P.; resources, H.W.; data curation, Y.W. and Y.D.; writing — original draft preparation, H.P.; writing—review and editing, H.P. and B.F.; visualization, B.F.; supervision, J.Y.; project administration, D.Y.L. and J.Y.; funding acquisition, H.P. and Y.D. 
Funding: This research was funded by the National Natural Science Foundation of China, grant number 51774006 and NSFC-Iron and Steel Joint Fund of the National Natural Science Foundation of China, grant number U1860105; the Natural Science Foundation of Anhui Province, grant number 1708085ME116 and the Key Research and Development Projects of Hebei Province, grant number 18211045.

Conflicts of Interest: The authors declare no conflict of interest.

\section{References}

1. Zhao, H.; Rama, S.C.; Barber, G.C.; Wang, Z.; Wang, X.J. Experimental study of deep drawability of hot rolled IF steel. Mater. Process. Technol. 2002, 128,73-79. [CrossRef]

2. Mei, L.; Chen, X.-P.; Huang, G.-J.; Liu, Q. Improvement of mechanical properties of a cryorolled Al-Mg-Si alloy through warm rolling and aging. J. Alloys Compd. 2019, 777, 259-263. [CrossRef]

3. Tang, Y.; Le, Q.-C.; Jia, W.-T.; Liu, X.; Cui, J.-Z. Influences of warm rolling and annealing processes on microstructure and mechanical properties of three parent structures containing Mg-Li alloys. Mater. Sci. Eng. A 2018, 711, 1-11. [CrossRef]

4. Babacan, N.; Bilal, M.; Hayrettin, C.; Liu, J.; Benafan, O.; Karaman, I. Effects of cold and warm rolling on the shape memory response of Ni50Ti30Hf20 high-temperature shape memory alloy. Acta Mater. 2018, 157, 228-244. [CrossRef]

5. Lv, L.-F.; Fu, L.-M.; Sun, Y.-L.; Shan, A.-D. An investigation on the microstructure and mechanical properties in an ultrafine lamellar martensitic steel processed by heavy warm rolling and tempering. Mater. Sci. Eng. A 2018, 731, 369-376. [CrossRef]

6. Zhang, R.; Cao, W.-Q.; Peng, Z.-J.; Shi, J.; Dong, H.; Huang, C.-X. Intercritical rolling induced ultrafine microstructure and excellent mechanical properties of the medium-Mn steel. Mater. Sci. Eng. A 2013, 583, 84-88. [CrossRef]

7. Guo, Z.-K.; Li, L.-F. Influences of alloying elements in warm deformation behavior of high-Mn TRIP steel with martensitic structure. Mater. Des. 2016, 89, 665-675. [CrossRef]

8. Hui, W.-J.; Shao, C.-W.; Zhang, Y.-J.; Zhao, X.-L.; Weng, Y.-Q. Microstructure and mechanical properties of medium Mn steel containing 3\%Al processed by warm rolling. Mater. Sci. Eng. A 2017, 707, 501-510. [CrossRef]

9. Hu, B.; Luo, H.-W. A strong and ductile 7Mn steel manufactured by warm rolling and exhibiting both transformation and twinning induced plasticity. J. Alloys Compd. 2017, 725, 684-693. [CrossRef]

10. Shao, C.-W.; Hui, W.-J.; Zhang, Y.-J.; Zhao, X.-L.; Weng, Y.-Q. Effect of intercritical annealing time on hydrogen embrittlement of warm rolled medium Mn steel. Mater. Sci. Eng. A 2018, 726, 320-331. [CrossRef]

11. Timokhina, I.B.; Nosenkov, A.I.; Humphreys, A.O.; Jonas, J.J.; Pereloma, E.V. Effect of Alloying Elements on the Microstructure and Texture of Warm Rolled Steels. ISIJ Int. 2004, 44, 717-724. [CrossRef]

12. Barnett, M.R.; Jonas, J.J. Influence of Ferrite Rolling Temperature on Grain Size and Texture in Annealed Low C and IF Steels. ISIJ Int. 1997, 37, 706-714. [CrossRef]

13. Quadir, M.Z.; Duggan, B.J. A microstructural study of the origins of c recrystallization textures in $75 \%$ warm rolled IF steel. Acta Mater. 2006, 54, 4337-4350. [CrossRef]

14. Tomitz, A.; Kaspar, R. Deep-Drawable Thin-gauge Hot Strip of Steel as a Substitution for Cold Strip. ISIJ Int. 2000, 40, 927-931. [CrossRef]

15. Jonas, J.J. Effect of shear band formation on texture development in warm-rolled IF steels. J. Mater. Process. Technol. 2001, 117, 293-299. [CrossRef]

16. Haldar, A.; Huang, X.; Leffers, T.; Hansen, N.; Ray, R.K. Grain orientation dependence of microstructures in a warm rolled IF steel. Acta Mater. 2004, 52, 5405-5418. [CrossRef]

17. Barnett, M.R. Role of In-grain Shear Bands in the Nucleation of $<111>/ /$ ND Recrysta Ilization Textures in Warm Rolled Steel. ISIJ Int. 1998, 38, 78-85. [CrossRef]

18. Okamoto, K.; Wakamiya, Y.; Shimoda, N.; Itoh, T. Process Control System of UltraThin Strip Production line at Tangshan Iron and Steel Group Co. in China. IFAC Proc. 2003, 36, 263-268. [CrossRef]

19. Arvedi, G.; Mazzolari, F.; Siegl, J.; Hohenbichler, G.; Holleis, G. Arvedi ESP first thin slab endless casting and rolling results. Ironmak. Steelmak. 2010, 37, 271-275. [CrossRef]

20. Linzer, B.; Jungbauer, A. Arvedi ESP for High-Quality Hot-Strip Production at Rizhao Steel. Mater. Sci. Forum 2016, 854, 207-214. [CrossRef] 
21. Jia, M.-X.; Lü, Y.-P.; Xu, L.-F.; Song, Y.-P. The Influence of Friction on the Texture Formation of an IF Steel during Hot Rolling in the Ferrite Region. Steel Res. Int. 2013, 84, 761-765. [CrossRef]

22. Guo, W.-M.; Wang, Z.-C.; Liu, S.; Wang, X.-B. Effects of Finish Rolling Temperature on Microstructure and Mechanical Properties of Ferritic-Rolled P-Added High Strength Interstitial-Free Steel Sheets. J. Iron Steel Res. Int. 2011, 18, 42-46. [CrossRef]

23. Um, K.-K.; Jeong, H.-T.; An, J.-K.; Lee, D.Y.; Kim, G.; Kwon, O. Effect of Initial Sheet Thickness on Shear Deformation in Ferritic Rolling of IF-Steel Sheets. ISIJ Int. 2000, 40, 58-64. [CrossRef]

24. Matsuoka, S.; Moritao, M.; Furukimi, S.; Obara, T. Effect of Lubrication Condition on Recrystallization Texture of Ultra-low C Sheet Steel Hot-rolled in Ferrite Region. ISIJ Int. 1998, 38, 633-639. [CrossRef]

25. Barrett, C.J. Influence of lubrication on through thickness texture of ferritically hot rolled interstitial free steel. Ironmak. Steelmak. 1999, 26, 393-397. [CrossRef]

26. Kong, N.; Tieu, K.; Zhu, H.-T.; Zhu, Q.; Gandy, P. Effects of Lubrication in Ferrite Rolling of Interstitial Free Steel. Mater. Sci. Forum 2014, 773-774, 186-191. [CrossRef]

27. Wang, Z.-D.; Guo, Y.-H.; Zhao, Z.; Liu, X.-H.; Wang, G.-D. Effect of Processing Condition on Texture and Drawability of a Ferritic Rolled and Annealed Interstitial-Free Steel. J. Iron Steel Res. Int. 2006, 13, 60-65. [CrossRef]

28. Bunge, H.J. Texture Analysis in Materials Science; Butterworths: London, UK, 1982.

29. Wang, Q.Y.; Zhu, Y.; Guo, S.; Zhang, Q.B.; Chi, B.B. Research on mixed lubrication characteristics of strip mill based on surface roughness features of rolling interface. J. Central South Univ. (Sci. Technol.) 2019, 50, 83-90.

30. Sun, J.L.; Ma, Y.L.; Zhang, Z.C.; Wang, J.Z. Effect of Different Lubrication Conditions on Surface Oxidation of Hot Rolled Strip. J. Univ. Sci. Technol. Beijing 2006, 28, 45-47.

31. Zhu, Z.X.; Sun, J.L.; Gao, Y.; Zhao, H.X. Experiment and Search of the Relationship between Hot-rolling Lubrication in Deforming Zone and Surface Quality of Steel Strip. J. Mech. Eng. 2012, 48, 133-137. [CrossRef]

32. Park, Y.B.; Kestens, L.; Jonas, J.J. Effect of Internal Stresses in Cold Rolled IF Steel on the Orientations of Recrystallized Grains. ISIJ Int. 2000, 40, 393-401. [CrossRef]

33. Mao, W.M.; Zhang, X.M. Quantitative Texture Analysis of Crystalline Materials; Metallurgical Industry Press: Beijing, China, 1995.

34. Schlippenbach, U.V.; Emren, F.; Lücke, K. Investigation of the development of the cold rolling texture in deep drawing steels by ODF-analysis. Acta Metall. 1986, 34, 1289-1301. [CrossRef]

35. Hirsch, J.; Lücke, K.; Hatherly, M. Mechanism of deformation and development of rolling textures in polycrystalline f.c.c. Metals-III. The influence of slip inhomogeneities and twinning. Acta Metall. 1988, 36, 2905-2927. [CrossRef]

36. Shen, K.; Duggan, B.J. Microbands and crystal orientation metastability in cold rolled interstitial-free steel. Acta Mater. 2007, 55, 1137-1144. [CrossRef]

37. Park, J.T.; Szpunar, J.A. Evolution of recrystallization texture in non-oriented electrical steels. Acta Mater. 2003, 51, 3037-3051. [CrossRef]

38. Park, J.T.; Szpunar, J.A.; Kim, J.K. Texture development during final annealing in non-oriented electrical steels. Mater. Sci. Forum 2005, 495-497, 471-476. [CrossRef]

39. Ray, R.K.; Jonas, J.J.; Hook, R.E. Cold rolling and annealing textures in low carbon and extra low carbon steels. Int. Mater. Rev. 1994, 39, 129-172. [CrossRef]

(C) 2019 by the authors. Licensee MDPI, Basel, Switzerland. This article is an open access article distributed under the terms and conditions of the Creative Commons Attribution (CC BY) license (http://creativecommons.org/licenses/by/4.0/). 